\title{
Blowin' in the wind
}

Whether clinging to a sock, surfing the breeze or sliding through an animal's gut, seeds have been beautifully designed by evolution for dispersal. They first appeared 360 million years ago and have helped plants colonize much of Earth's surface. True time capsules of life, seeds may travel thousands of miles and wait for many years until they encounter the right conditions for germination.

In Seeds: Time Capsules of Life (Papadakis, E35/Firefly, \$60), artist Rob Kesseler and seed morphologist Wolfgang Stuppy, both of the Royal Botanic Gardens at Kew, present a natural history of seeds, showcasing their specialized architecture in stunning close-up photographs and scanning electron micrographs. The walls of the 'balloon' seed of the yellow paintbrush (Castilleja flava) shown here have dissolved, leaving a honeycombed cage ready to ride the wind.

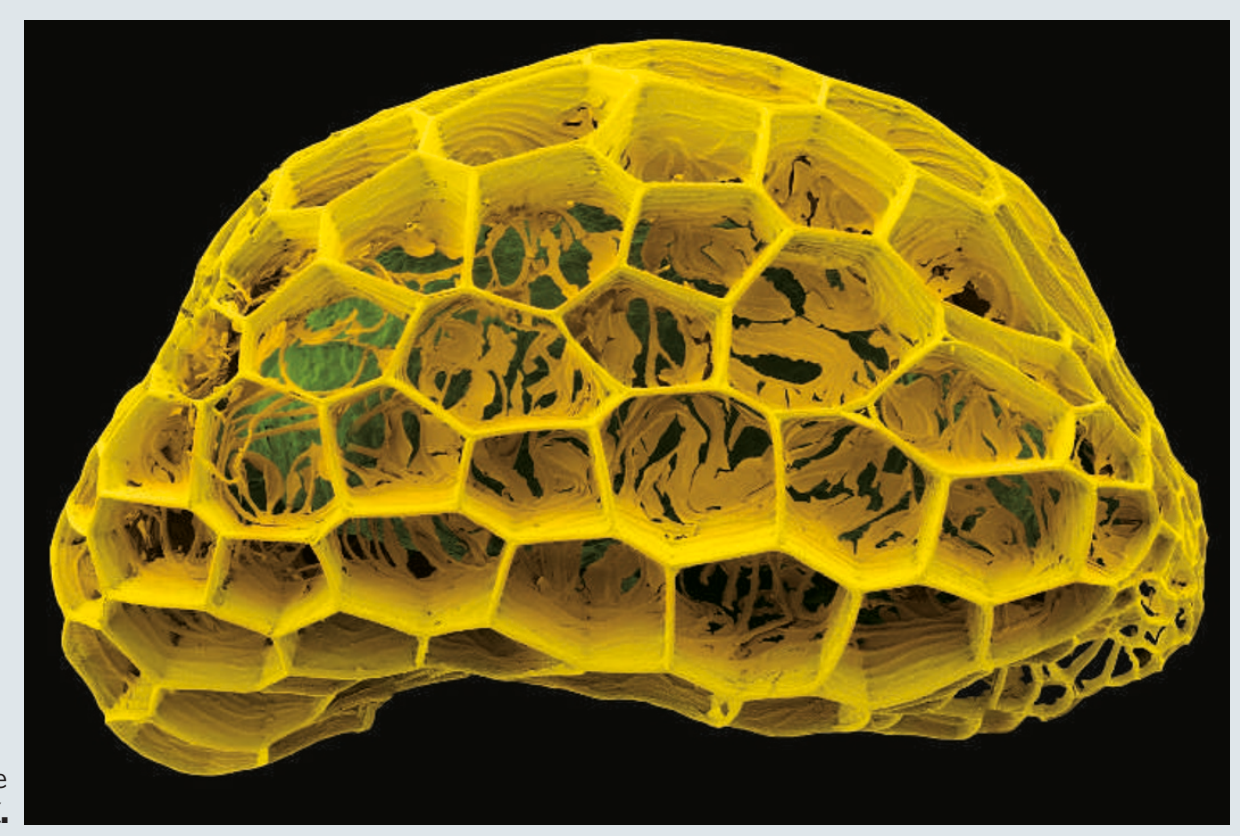

\section{A pro-darwinian tool-kit}

\section{Darwinism and its Discontents by Michael Ruse \\ Cambridge University Press: 2006. 328 pp. $\$ 19.99, \$ 30$}

\section{Mark Pagel}

In the UK House of Lords, peers who vote for a piece of legislation are called the 'contents' and those who vote against it are called the 'not contents'. They are not called 'discontents' or 'malcontents', and this is an important distinction. Being merely not content gives hope that were the legislation to be modified, a not content could move to the content lobby. To be discontented connotes something more extreme - a disaffection or dislike. Worse yet, malcontents evince seditious or even treasonous leanings.

Michael Ruse, then, has probably chosen the title of his new book, Darwinism and its Discontents, accurately. What seems clear from the attention received by critics of darwinism - the creationists and the proponents of 'intelligent design' - is that they are more than merely not content with darwinism; they are disaffected, they actively do not like darwinism. The distinction is, again, important.

The book is not a sociological study of the discontents; Ruse does not tell us who they are or even whether they are large in number. Rather, it is a sort of 'battle book', containing facts about evolution and natural selection, and is designed to be instructive in changing people's minds about darwinism. But creationists' disaffection with darwinism may only be cloaked in quibbles about design, the age of Earth, fossils, missing links and the importance of the peppered moth, Biston betularia.
These concerns may conceal a deeper affective — indeed a limbic - response to the theory.

This divide between the disaffected and the merely uninformed or misinformed may be why it is so difficult to get anti-darwinists to join the contents. If it is repellent for a creationist to believe facts about evolution and geology, trying to persuade them by using more such unpleasant facts may be a struggle. Daniel Dennett memorably described darwinian theory as a 'universal acid' capable of dissolving all biological facts dropped into it. But religious belief effortlessly bats away empirical and philosophical challenges, making darwinism appear about as acidic as baby lotion. It is as if nothing less than a visit from God himself saying "Don't worry, darwinism is true, I made it that way" will provide the reassurance that believing in evolution is not a one-way ticket to Dante's seventh circle of hell.

Failing help from above, darwinists can only do what they can: indefatigably and hopefully chip away at the edifice of wrong beliefs that underpin the views of discontents. The jacket to Darwinism and its Discontents says the book "will appeal" to "concerned citizens who worry that Darwinism is a naturalistic religion that is forced on schoolchildren". It may be optimistic to think it will appeal to these people. But Ruse's biographical chapter on Darwin, an informative survey of how known facts of biology fit the theory of evolution, and well-framed chapters on the origin of life, descent with modification and human evolution, form a concise tool-kit of pro-darwinian chisels. Whether the discontents use these newly acquired chisels on themselves, or have them used on them by well-meaning friends, teachers or parents, does not really matter.

As a philosopher, Ruse is well placed to discuss darwinism's ethical, religious and philosophical dimensions. If the discontents stay with his book long enough to reach its later chapters, they will find material that transcends the conventional empirical challenges to their disbelief. A common misunderstanding of darwinism is that, somehow, the facts of biology about mere animals are pointers to the characteristics of humankind. This belief has been called the 'naturalistic fallacy', and is a conflation of what is and what ought to be the case, wrongly justifying in humans all sorts of activities from sex discrimination to aggression. More broadly, some believe in what philosophers call 'evolutionary epistemology' - that the ways we behave and the views we hold must be accurate reflections of the true nature of the world, otherwise natural selection would not have favoured them.

Of course, deductions from evolutionary epistemology, although undoubtedly sometimes true, are formally wrong, not least because culture has allowed humans, probably uniquely in degree, to weaken the links to their biology. Ruse sums it up nicely: "No one is surprised that Mendel, who was right about heredity, had no children, and that Darwin, who was wrong about heredity, had ten children." Equally, this seemingly obvious point should give the discontents of Ruse's title pause. Religion is found in all human cultures, and most include creation stories not unlike those of the major religions. But this universality, although perhaps signalling some human predilection to hold religious views, should not necessarily reassure: superstition is also universal. Mark Pagel is professor of evolutionary biology, School of Biological Sciences, University of Reading, Reading RG6 6AJ, UK. 